\title{
Enhanced light absorption by mixed source black and brown carbon particles in UK winter
}

Shang Liu ${ }^{1,2}$, Allison C. Aiken ${ }^{1}$, Kyle Gorkowski1,3, Manvendra K. Dubey ${ }^{1}$, Christopher D. Cappa ${ }^{4}$, Leah R. Williams ${ }^{5}$, Scott C. Herndon ${ }^{5}$, Paola Massoli ${ }^{5}$, Edward C. Fortner ${ }^{5}$, Puneet S. Chhabra ${ }^{5,6}$, William A. Brooks ${ }^{5}$, Timothy B. Onasch ${ }^{5,7}$, John T. Jayne ${ }^{5}$, Douglas R. Worsnop ${ }^{5}$, Swarup China ${ }^{8}$,

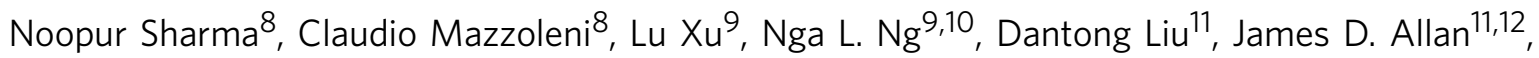
James D. Lee ${ }^{13}$, Zoë L. Fleming ${ }^{14}$, Claudia Mohr ${ }^{15,16}$, Peter Zotter ${ }^{17,18}$, Sönke Szidat ${ }^{19}$ \& André S.H. Prévôt ${ }^{17}$

Black carbon (BC) and light-absorbing organic carbon (brown carbon, $\mathrm{BrC}$ ) play key roles in warming the atmosphere, but the magnitude of their effects remains highly uncertain. Theoretical modelling and laboratory experiments demonstrate that coatings on BC can enhance $B C$ 's light absorption, therefore many climate models simply assume enhanced BC absorption by a factor of $\sim 1.5$. However, recent field observations show negligible absorption enhancement, implying models may overestimate $B C^{\prime} s$ warming. Here we report direct evidence of substantial field-measured $B C$ absorption enhancement, with the magnitude strongly depending on $B C$ coating amount. Increases in $B C$ coating result from a combination of changing sources and photochemical aging processes. When the influence of $\mathrm{BrC}$ is accounted for, observationally constrained model calculations of the $\mathrm{BC}$ absorption enhancement can be reconciled with the observations. We conclude that the influence of coatings on $\mathrm{BC}$ absorption should be treated as a source and regionally specific parameter in climate models.

\footnotetext{
${ }^{1}$ Earth and Environmental Sciences Division, Los Alamos National Laboratory, Los Alamos, New Mexico 87545, USA. ${ }^{2}$ Cooperative Institute for Research in the Environmental Sciences and Department of Chemistry and Biochemistry, University of Colorado, Boulder, Colorado 80309, USA. ${ }^{3}$ Department of Civil and Environmental Engineering, Carnegie Mellon University, Pittsburgh, Pennsylvania 15213, USA. ${ }^{4}$ Department of Civil and Environmental Engineering, University of California, Davis, California 95616, USA. ${ }^{5}$ Aerodyne Research, Inc. Billerica, Massachusetts 01821, USA. ${ }^{6}$ Department of Chemical Engineering, University of Texas at Austin, Austin, Texas 78712, USA. ${ }^{7}$ Department of Chemistry, Boston College, Boston, Massachusetts 02467, USA. 8 Physics Department and Atmospheric Sciences Program, Michigan Technological University, Houghton, Michigan 49931, USA. ${ }^{9}$ School of Chemical and Biomolecular Engineering, Georgia Institute of Technology, Atlanta, Georgia 30332, USA. ${ }^{10}$ School of Earth and Atmospheric Sciences, Georgia Institute of Technology, Atlanta, Georgia 30332, USA. ${ }^{11}$ School of Earth, Atmospheric and Environmental Science, University of Manchester, Manchester M13 9PL, UK. ${ }^{12}$ National Centre for Atmospheric Science, University of Manchester, Manchester M13 9PL, UK. ${ }^{13}$ Wolfson Atmospheric Chemistry Laboratory and National Centre for Atmospheric Science, University of York, York Y010 5DD, UK. ${ }^{14}$ National Centre for Atmospheric Science, Department of Chemistry, University of Leicester, Leicester LE1 7RH, UK. ${ }^{15}$ Department of Atmospheric Sciences, University of Washington, Seattle, Washington 98195, USA. ${ }^{16}$ Institute for Meteorology and Climate Research, Karlsruhe Institute of Technology, Eggenstein-Leopoldshafen 76344, Germany. ${ }^{17}$ Laboratory of Atmospheric Chemistry, Paul Scherrer Institute, Villigen 5232, Switzerland. ${ }^{18}$ Lucerne School of Engineering and Architecture, Bioenergy Research, Lucerne University of Applied Sciences and Arts, Horw 6048, Switzerland. ${ }^{19}$ Department of Chemistry and Biochemistry and Oeschger Centre for Climate Change Research, University of Bern, Bern 3012, Switzerland. Correspondence and requests for materials should be addressed to S.L. (email: shang.liu@colorado.edu) or to M.K.D. (email: dubey@lanl.gov).
} 
Q uantitative prediction of the direct warming effect of absorbing carbonaceous particles is challenging but crucial to assess their climate forcing ${ }^{1-4}$. The major atmospheric absorbing carbonaceous components are black carbon (BC) and brown carbon $(\mathrm{BrC})$. BC strongly absorbs across the solar spectrum, whereas $\mathrm{BrC}$ preferentially absorbs at short wavelength ${ }^{2,5}$. Uncertainties in the absorptive properties of $\mathrm{BC}$ and $\mathrm{BrC}$ contribute substantially to the total uncertainty estimates of their direct warming effects, in addition to other uncertainties associated with emission estimates, atmospheric transport simulations, and removal rates. Bond et al. ${ }^{6}$ suggest that the mass absorption cross-section $(M A C)$ of uncoated $\mathrm{BC}$ has an uncertainty of $16 \%$ at $550 \mathrm{~nm}$. Additional uncertainties in absorption can be introduced as the optical features of $\mathrm{BC}$ are continuously modified during atmospheric aging processes. These aging processes mix $\mathrm{BC}$ with non- $\mathrm{BC}$ species, including $\mathrm{BrC}$. Such mixing, and more specifically formation of coatings on $\mathrm{BC}$ particles, can occur over a few hours after $\mathrm{BC}$ emission and continue for days ${ }^{7}$. The coatings can enhance the absorption above that of uncoated BC particles through the so-called 'lensing effect.' The lensing effect has been confirmed by theoretical calculations ${ }^{8-11}$ and laboratory measurements ${ }^{12-16}$ but is not in line with field observations, discussed further below. The inconsistency suggests that using a lensing effect calculated from Mie theory may introduce $\sim 50 \%$ uncertainty in BC's absorption, which can translate to $\sim 50 \%$ uncertainty of modelled BC's direct warming effect. An additional uncertainty of $\sim 20 \%$ may be introduced when including the absorption of $\mathrm{BrC}^{4}$, which is ignored by most current climate models. Accordingly, it is important to constrain the dynamic absorptive properties of $\mathrm{BC}$ and $\mathrm{BrC}$ to improve model predictions.

The influence of $\mathrm{BC}$ coatings on BC's absorption has been studied theoretically and experimentally in the laboratory and in the field. Mie theory calculations that assume spherical BC-containing particles with a core-shell configuration, such as those employed by many current climate models, indicate that enhancement factors of up to 3 are plausible ${ }^{8-11}$. Laboratory studies demonstrate that such absorption enhancement can occur $^{12-16}$. Therefore, current climate models typically either calculate an enhancement factor based on simplified mixing-state assumptions $^{17,18}$ or assume a constant enhancement value of $\sim 1.5$ for calculating BC absorption ${ }^{19,20}$. In contrast, field observations of $\mathrm{BC}$ absorption enhancement in urban and coastal California (USA) and Japan ${ }^{14,21,22}$ yield small values (on average no more than 1.1 at 405,532 , and $781 \mathrm{~nm}$ ), even when substantial coatings are present ${ }^{14,21}$. If true globally, this result questions $\mathrm{BC}$ 's role as the second most important anthropogenic climate warmer after carbon dioxide ${ }^{1,3}$. The difference may be due to a preponderance of ambient $\mathrm{BC}$ being only partially encapsulated or attached to the host particle surface ${ }^{23}$. However, larger absorption enhancements of 1.4 (at $532 \mathrm{~nm}$ ) have been observed in air masses strongly impacted by biomass burning ${ }^{24}$. Because of the paucity of comprehensive ambient measurements, the mechanisms responsible for the model-observation discrepancies remain elusive, underscoring the need for field studies in other representative environments, in particular those with mixed $\mathrm{BC}$ and $\mathrm{BrC}$ sources.

We perform an in-depth field study of light absorption enhancement factors $\left(E_{\mathrm{abs}}\right)$ for $\mathrm{BC}$ particles emitted from fossil fuel and residential burning sources in wintertime UK. The measurements are part of the 2012 Clean Air for London (ClearfLo) project ${ }^{25}$ at Detling, a rural site $45 \mathrm{~km}$ southeast of central London. We demonstrate substantial light absorption enhancement of $\mathrm{BC}$ from our measurements. Through detailed chemical and microphysical analyses, we find that the magnitude of the observed $E_{\text {abs }}$ strongly depends on the amount of coatings on $\mathrm{BC}$, the $\mathrm{BC}$ sources, and the extent of particle aging. We also show that the $E_{\text {abs }}$ at $405 \mathrm{~nm}$ is affected by low-volatility $\mathrm{BrC}$. In addition to the observations, we systematically examine the theoretically calculated $E_{\text {abs }}$ and determine the refractive indices for $\mathrm{BC}$ and $\mathrm{BrC}$ that result in agreement between calculated and observed $E_{\text {abs. }}$. Furthermore, single-particle morphological analysis provides mechanistic insight of $E_{\text {abs }}$ in comparison to previous studies. In light of these analyses, we conclude that the $E_{\text {abs }}$ is source and regionally dependent. Therefore, parameters used for Mie modelling should be calibrated with observations to account for this effect.

\section{Results}

Direct observation of $\boldsymbol{E}_{\text {abs }}$. Observed $E_{\text {abs }}$ values were calculated using two independent and complementary methods. In one, $E_{\text {abs }}$ was taken as the ratio between the $M A C$ observed for ambient particles and for particles heated at $250^{\circ} \mathrm{C}$. $\mathrm{BC}$ is typically considered refractory at these temperatures and the heating is therefore used to remove the part of the coating material that is volatile. Particle heating was achieved by passing particles through a heated thermodenuder (TD). MAC is defined as the ratio of the absorption coefficient $\left(b_{\mathrm{abs}}\right)$ to refractory $\mathrm{BC}(\mathrm{rBC})$ concentration $([\mathrm{rBC}]): M A C=b_{\mathrm{abs}} /[\mathrm{rBC}] . b_{\mathrm{abs}}$ at 405 and $781 \mathrm{~nm}$ were quantified using photoacoustic spectroscopy ${ }^{26}$ and $[\mathrm{rBC}]$ was measured using a single-particle soot photometer (SP2) 27,28 . Normalizing $b_{\mathrm{abs}}$ by [rBC] accounted for particle losses in the TD and temporal variations of $b_{\text {abs }}$ during each ambient and TD measurement cycle. The observed $E_{\text {abs }}$ calculated using this method is termed $E_{\text {abs - obs - TD ( }}^{\lambda} \lambda$ denotes wavelength). The campaign average $E_{\text {abs - obs - TD }}^{405}$ and $E_{\text {abs - obs - TD values were } 1.3}^{781}$ and 1.4, respectively, with their time series and frequency distributions shown in Supplementary Fig. 1. The second method was based on the absolute MAC values for ambient particles and the estimated enhancement is termed $E_{\text {abs - obs - MAC. }}^{\lambda}$. $E_{\text {abs }- \text { obs }- \text { MAC }}^{\lambda}$ was calculated as $M A C_{\mathrm{obs}}^{\lambda} / M A C_{\mathrm{ref}}^{\lambda}$, where $M A C_{\mathrm{obs}}$ is the absolute MAC for ambient particles (shown in Supplementary Fig. 2.), and $M A C_{\text {ref }}$ is the literature reference value for uncoated $\mathrm{BC}\left(7.5 \pm 1.2 \mathrm{~m}^{2} \mathrm{~g}^{-1} \text { at } 550 \mathrm{~nm}\right)^{6}$. Using the inverse wavelength dependence relationship for uncoated $\mathrm{BC}^{6}$, we derived $M A C_{\text {ref }}$ values of $10.2 \pm 1.6$ and $5.3 \pm 0.8 \mathrm{~m}^{2} \mathrm{~g}^{-1}$ at 405 and $781 \mathrm{~nm}$, respectively.

Since $\mathrm{BrC}$ absorbs at $405 \mathrm{~nm}$ but not at $781 \mathrm{~nm}$, the observed $E_{\text {abs }}$ at $405 \mathrm{~nm}$ (using both methods) includes the lensing-driven enhancement and the enhancement induced by semi-volatile $\mathrm{BrC}$, whereas the observed $E_{\text {abs }}$ at $781 \mathrm{~nm}$ represents the lensing-driven enhancement only. A glossary of the abbreviations used in this study is listed in Supplementary Table 1.

Effects of internal mixing on $E_{\text {abs. }}$. We measured the composition of total non-refractory organic mass $(\mathrm{OM})$ in submicron particles using a high-resolution time-of-flight aerosol mass spectrometer (HR-ToF-AMS ${ }^{29,30}$ and the non-refractory OM internally mixed with $\mathrm{BC}$ with a soot particle aerosol mass spectrometer (SP-AMS) ${ }^{31}$. The SP-AMS was operated in laseronly mode, which allows for detection of only $\mathrm{rBC}$-containing particles (Methods). The ratio of non-rBC mass to $\mathrm{rBC}$ mass in rBC-containing particles is termed $R_{\mathrm{BC}}$. Assuming a core-shell particle configuration, $R_{\mathrm{BC}}$ is a measure of relative coating thickness.

The observed $E_{\text {abs }}$ at Detling increased substantially with increasing $R_{\mathrm{BC}}$ (Fig. 1a,b) unlike the previous studies in California ${ }^{14,21}$, even though the maximum $R_{\mathrm{BC}}$ values observed here were three times smaller. In our study, there was good agreement between $E_{\text {abs - obs - MAC }}^{781}$ and $E_{\text {abs - obs - TD }}^{781}$ where $\mathrm{BrC}$ is thought to absorb negligibly. This result indicates that a 

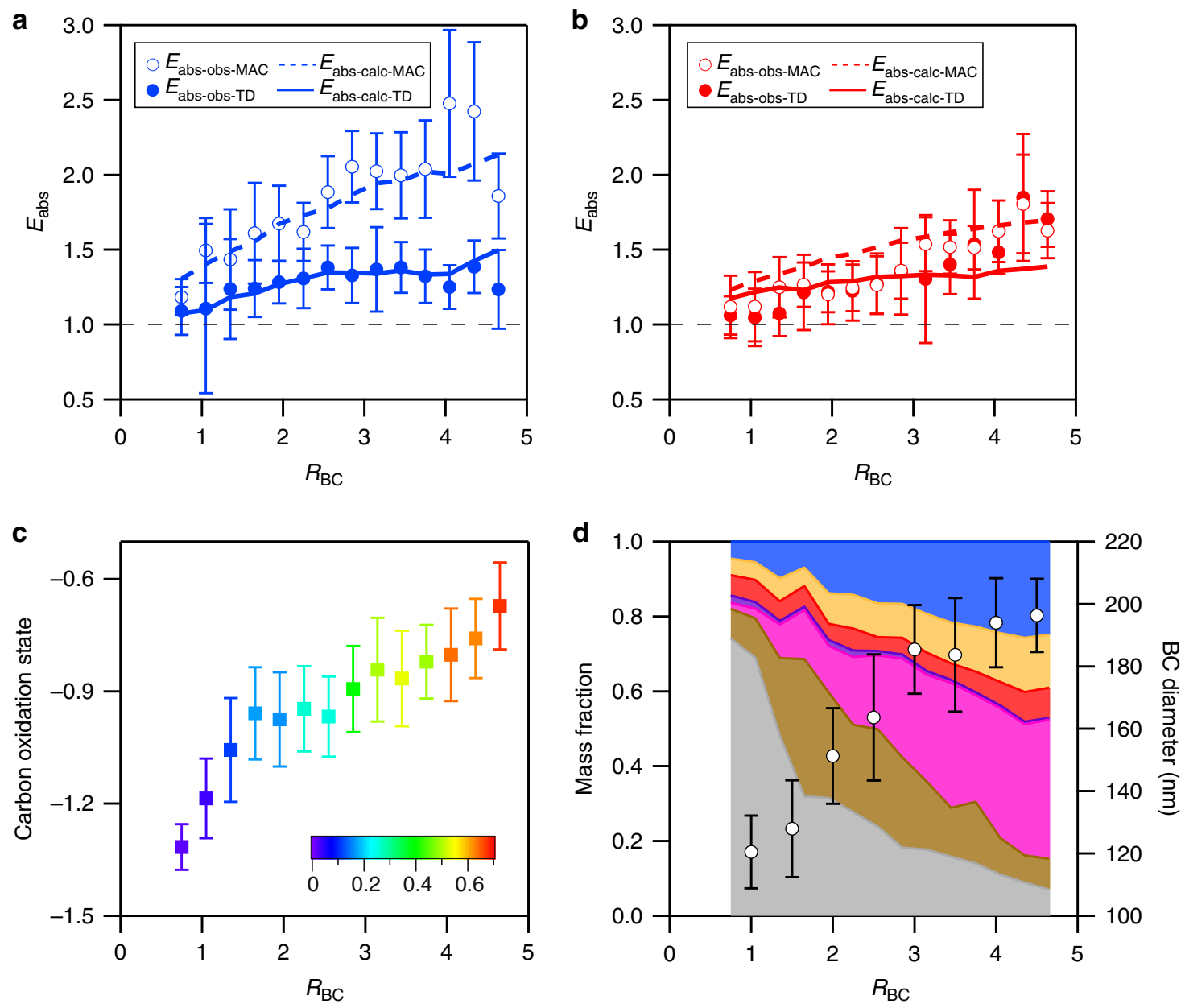

Figure 1 | Variation of $\boldsymbol{E}_{\mathrm{abs}}$ and particle composition as a function of $\boldsymbol{R}_{\mathrm{BC}} \cdot(\mathbf{a}, \mathbf{b})$ show measured and calculated absorption enhancement values versus $R_{\mathrm{BC}}$ at 405 and $781 \mathrm{~nm}$, respectively. $\mathrm{k}_{\mathrm{BrC}}$ of 0.004 and 0.032 were used for modelling absorption of ambient and thermodenuded organic mass at $405 \mathrm{~nm}$, respectively. (c) Particle average oxidation state versus $R_{\mathrm{BC}}$. The points are coloured by the organic mass fraction of the oxygenated organic aerosol factor, which was derived from factor analysis of the BC-associated OM. (d) Mass fraction of the non-refractory components internally mixed with BC (shaded areas) and $\mathrm{BC}$ core median volume-weighted diameter (open circles) as a function of $R_{\mathrm{BC}}$. The colours represent nitrate (blue), ammonium (orange), sulfate (red), chloride (purple), oxygenated organic aerosol factor (pink), solid fuel organic aerosol factor (brown) and hydrocarbon-like organic aerosol factor (grey). The error bars in (a-d) represent s.d. of the values for each $R_{\mathrm{BC}}$ interval.

lensing-driven absorption enhancement was, at times, substantial in Detling. It also suggests that residual non-rBC materials did not have a notable impact on absorption by the thermodenuded particles. In contrast, $E_{\mathrm{abs}-\mathrm{obs}-\mathrm{MAC}}^{405}$ was notably higher than

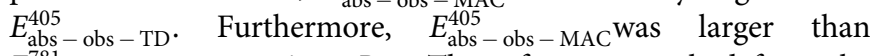
$E_{\mathrm{abs}-\mathrm{obs}-\mathrm{MAC}}^{781}$ at a given $R_{\mathrm{BC}}$. These features resulted from the direct contribution of $\mathrm{BrC}$ on the absorption at $405 \mathrm{~nm}$.

As $\mathrm{BrC}$ contributes to the absorption at $405 \mathrm{~nm}$, it is necessary to separate the absorption by $\mathrm{BrC}$ and evaluate the effect of $\mathrm{BrC}$ on $E_{\text {abs }}$ at $405 \mathrm{~nm}$. $b_{\text {abs }}$ at $405 \mathrm{~nm}\left(b_{\mathrm{abs}}^{405}\right)$ was apportioned into absorption by residual BC (BC and low-volatility coatings on BC that remain on the particles after thermodenuding at $250^{\circ} \mathrm{C}$ ), low-volatility $\mathrm{BrC}$ that did not fully evaporate in the $\mathrm{TD}\left(\mathrm{BrC}_{\mathrm{LV}}\right)$, semi-volatile $\mathrm{BrC}$ that evaporated in the $\mathrm{TD}\left(\mathrm{BrC}_{\mathrm{SV}}\right)$, and the increment of $\mathrm{BC}$ absorption due to the lensing effect, with their respective fractions of $53,24,7$ and $16 \%$ (Methods). The apportioned values were similar to the apportionment results of Lack et $a .^{24}$ at $404 \mathrm{~nm}$ inside a wildfire plume (Supplementary Table 2), even though we sampled a mixture of regional fossil fuel and residential burning sources with much lower absorption and $\mathrm{OM}$ concentrations. Given that the absorption of $\mathrm{BrC}_{\mathrm{LV}}$ was 3.4 times the absorption of $\mathrm{BrC}_{\mathrm{SV}}$ and that the mass of $\mathrm{BrC}_{\mathrm{LV}}$ was only $9.3 \%$ of the mass of $\mathrm{BrC}_{\mathrm{SV}}$ (measured by the HR-ToF-AMS assuming all $\mathrm{OM}$ is $\mathrm{BrC}$ ), we estimated that the $M A C$ of the $\mathrm{BrC}_{\mathrm{LV}}$ was $\sim 36$ times the $M A C$ of $\mathrm{BrC}_{\mathrm{SV}}$. The much higher $M A C$ of $\mathrm{BrC}_{\mathrm{LV}}$ was likely because $\mathrm{BrC}_{\mathrm{LV}}$ contained larger molecules with more conjugated carbon bonds (compared with $\mathrm{BrC}_{\mathrm{SV}}$ ) that have lower volatility. This result is consistent with a recent study that shows BrC absorption from biomass burning is mostly associated with compounds of extremely low volatility ${ }^{32}$. Since the total non-refractory $\mathrm{OM}$ was substantially greater than the non-refractory $\mathrm{OM}$ that was associated with $\mathrm{rBC}$, it is likely that much of the $\mathrm{BrC}$ was externally mixed with $\mathrm{rBC}$.

The observed $E_{\mathrm{abs}}$ at $405 \mathrm{~nm}$ using the TD method was affected by $\mathrm{BrC}_{\mathrm{LV}}$. The increase of $\mathrm{BrC}_{\mathrm{LV}}$ with $R_{\mathrm{BC}}$ (Supplementary Fig. 3a) suggests a larger contribution of $\mathrm{BrC}_{\mathrm{LV}}$ to the absorption of thermodenuded particles as the $\mathrm{rBC}$ coating thickness increased, resulting in lower $E_{\mathrm{abs}-\mathrm{obs}-\mathrm{TD}}^{405}$ at high $R_{\mathrm{BC}}$. As a result, $E_{\mathrm{abs}-\mathrm{obs}-\mathrm{TD}}^{405}$ leveled off for $R_{\mathrm{BC}}$ values greater than $\sim 3$ (Fig. 1a). In contrast, $E_{\mathrm{abs}-\mathrm{obs}-\mathrm{TD}}^{781}$ continuously increased with $R_{\mathrm{BC}}$ (Fig. 1b) as the absorption of $\mathrm{BrC}$ was negligible at $781 \mathrm{~nm}$.

Dependence of $\boldsymbol{E}_{\mathrm{abs}}$ on sources and aging. To elucidate the mechanisms causing the enhanced $\mathrm{BC}$ absorption and formation 
of $\mathrm{BrC}_{\mathrm{LV}}$, the $\mathrm{BC}$-associated OM (measured by the SP-AMS) and total OM (measured by the HR-ToF-AMS) were apportioned into linearly independent components using positive matrix factorization $^{33,34}$. The analysis resulted in three factors for both $\mathrm{BC}$-associated $\mathrm{OM}$ and total $\mathrm{OM}$, namely oxygenated organic aerosol, solid fuel organic aerosol, and hydrocarbon-like organic aerosol. Based on the mass spectra, correlations with source tracers, and correlations with air mass sources from back trajectories, the oxygenated organic aerosol components were associated with long-range transport and aging of particles, the solid fuel organic aerosol components were associated with solid fuel burning for residential heating including biomass and coal, and the hydrocarbon-like organic aerosol components were associated with traffic emissions. The organic carbon in the total oxygenated organic aerosol component (oxygenated organic carbon) was further separated into fossil and non-fossil fractions using a combination of radiocarbon $\left({ }^{14} \mathrm{C}\right)$, factor analysis, and BC source analyses (Methods). The apportionment showed that total oxygenated organic carbon (and likely BC-associated oxygenated organic carbon) was largely (73-90\%) derived from the non-fossil sources. In addition, we find that the absorption by $\mathrm{BrC}_{\mathrm{LV}}$ correlated with the total oxygenated organic aerosol component (Supplementary Fig. 3b), indicating that $\mathrm{BrC}_{\mathrm{LV}}$ may be secondary, as previous laboratory studies proposed ${ }^{35,36}$. In contrast, such correlation was not found for $\mathrm{BrC}_{\mathrm{SV}}$.

The variation of $E_{\mathrm{abs}}$ with $R_{\mathrm{BC}}$ was associated with changing sources as well as photochemical processing (Fig. 1c,d). The overall composition of $\mathrm{rBC}$-containing particles varied with $R_{\mathrm{BC}}$ (Fig. 1d). The relative abundance of secondary components (inorganics and oxygenated organic aerosol component) increased with $R_{\mathrm{BC}}$, while the relative abundance of primary components (hydrocarbon-like organic aerosol and solid fuel organic aerosol components) decreased. At lower $R_{\mathrm{BC}}$, the BC-associated OM was dominated by traffic sources and the $E_{\text {abs }}$ value $(\sim 1.1)$ was similar to the value observed at much higher $R_{\mathrm{BC}}$ by Cappa et al. ${ }^{14}$, in which fossil fuel combustion is the dominant source for BC. Since the total oxygenated organic carbon was largely from non-fossil sources, the increase in $R_{\mathrm{BC}}$ was correlated with changing sources that could produce $\mathrm{BC}$ particles in distinct size regimes. Given that $\mathrm{BC}$ particles from biomass burning are typically larger than those from fossil fuel combustion ${ }^{39}$, the correlation of BC core median volume-weighted diameter (measured by the SP2) with $R_{\mathrm{BC}}$ (Fig. 1d) was consistent with the oxygenated organic aerosol components being increasingly produced by biomass combustion related sources as the oxygenated organic aerosol concentration increased. The increase of $\mathrm{BC}$ diameter with $R_{\mathrm{BC}}$ may also indicate that coagulation during transport increased the $\mathrm{BC}$ size. However, since coagulation rates scale with the square of particle number (which decreases away from sources), and only coagulation between two BC-containing particles can lead to an increase in the BC core size, this hypothesis seems unlikely.

The increase in $R_{\mathrm{BC}}$ was correlated with an increasing average carbon oxidation state of BC-containing particles (Fig. 1c), which was calculated from the SP-AMS measured atomic O:C and $\mathrm{H}: \mathrm{C}$ ratios (oxidation state $=2 \times \mathrm{O}: \mathrm{C}-\mathrm{H}: \mathrm{C})^{38}$. The atomic O:C and $\mathrm{H}: \mathrm{C}$ ratios were calculated using the parameterization in Canagaratna et al. ${ }^{39}$ Particle oxidation state increases with atmospheric oxidation and was used as a proxy for particle photochemical age here (we do not have the necessary measurements to calculate photochemical age). The correlation of $R_{\mathrm{BC}}$ with oxidation state suggests that photochemical processes over long timescales were likely important for producing both organic and inorganic coatings on BC.
Comparison of calculated and observed $\boldsymbol{E}_{\text {abs }}$. An important consideration is the extent to which the observations are consistent with Mie theory calculations of BC absorption, as core-shell Mie theory is used in many current climate models. The $E_{\text {abs }}$ values were calculated using observationally constrained core-shell Mie theory (Methods) by either assuming that no $\left(E_{\text {abs-calc-MAC }}\right)$ or some $\left(E_{\text {abs-calc-TD }}\right)$ residual material remained both on the BC particles and as externally mixed particles after heating ${ }^{21}$. The $E_{\text {abs-calc-MAC }}$ and $E_{\text {abs-calc-TD }}$ were conceptually comparable to $E_{\text {abs-obs-MAC }}$ and $E_{\text {abs-obs-TD, respectively, assuming }}$ core-shell configuration for both ambient and thermodenuded BC-containing particles. An additional set of calculations were performed under the Rayleigh-Debye-Gans (RDG) approximation: The absorption by both uncoated and coated $\mathrm{BC}$ was determined by the properties of the individual spherules that made up a single BC particle ${ }^{40}$. The total absorption by a single particle is approximated as the sum of the absorption from individual spherules comprising a single particle, as calculated from spherical-particle Mie theory. As the size of the spherule was not explicitly known, and further might vary with the BC source, calculations were performed assuming spherules of 40 and $70 \mathrm{~nm}$ (diameter) to assess the sensitivity of the results to the assumed spherule size. To account for $\mathrm{BrC}$ contributions at $405 \mathrm{~nm}$, calculations were performed using a range of imaginary refractive indices for the $\mathrm{OM}$ to find solutions that match the observed values. The base case assumed that $\mathrm{OM}$ internally mixed with $\mathrm{BC}$ had the same refractive index as that externally mixed from BC, and that the refractive index of the ambient OM was the same as the residual $\mathrm{OM}$ after heating. Alternative cases were also considered, and results of the calculations are shown in Fig. 2.

Recalling that $E_{\text {abs-obs-TD }} \sim E_{\text {abs-obs-MAC }}$ at $781 \mathrm{~nm}$, the calculated $E_{\text {abs }}$ generally reproduced the observed trend with $R_{\mathrm{BC}}$ (Fig. 1b). Comparison with the observed values at $781 \mathrm{~nm}$ showed that: (1) $E_{\text {abs-calc-MAC }}$ overestimated observations by $14 \%$ when $R_{\mathrm{BC}}$ was smaller than 2.9 ; (2) $E_{\text {abs-calc-TD }}$ overestimated observations by $14 \%$ for $R_{\mathrm{BC}}<1.4$ and underestimated observations by $17 \%$ for $R_{\mathrm{BC}}>3.8$; and (3) $E_{\text {abs-calc-TD }}$ was less dependent on $R_{\mathrm{BC}}$ compared to $E_{\mathrm{abs}-\mathrm{obs}-\mathrm{TD}}$. However, the differences between calculated and observed absorption enhancement were comparable to the measurement uncertainty $(15 \%)$ of $E_{\text {abs-obs-TD. The }}$ difference between modelled $E_{\text {abs-calc-MAC }}$ and $E_{\text {abs-calc-TD }}$ at $781 \mathrm{~nm}$ resulted from (theoretical) contributions of residual coatings to the absorption by thermodenuded particles. As the observations suggested negligible contributions of residual coatings, this indicates that the $E_{\text {abs-calc-MAC }}$ overestimated the absorption enhancement due to the lensing effect for thermodenuded particles at a given $R_{\mathrm{BC}}$ compared with the observations.

The $E_{\text {abs-calc-MAC }}$ at $405 \mathrm{~nm}$ were lower than the observations when OM was assumed to be non-absorbing for both the Mie and RDG cases (Fig. 2), suggesting a role for BrC absorption. Direct absorption by the internally mixed $\mathrm{BrC}$ was very small compared with externally mixed $\mathrm{BrC}$, which was primarily a reflection of the much larger mass concentration of externally mixed OM compared with BC-associated OM. This was assessed by comparing two cases, one with a bulk, campaign average imaginary refractive index $\left(k_{\mathrm{BrC}}\right)$ of 0.008 and the other with $k_{\mathrm{BrC}}=0$ for the internally mixed OM while leaving $k_{\mathrm{BrC}}=0.008$ for the externally mixed OM. The difference in observed and calculated $E_{\text {abs-MAC }}$ can be reconciled if the ambient OM was assumed to be slightly absorbing, with a bulk, campaign average $k_{\mathrm{BrC}}=0.004$ for the Mie case, $k_{\mathrm{BrC}} \sim 0.008$ for $\mathrm{RDG}(70 \mathrm{~nm})$ case, and $k_{\mathrm{BrC}} \sim 0.012$ for the $\mathrm{RDG}(40 \mathrm{~nm})$ case at $405 \mathrm{~nm}$. The larger $k_{\mathrm{BrC}}$ required for $\mathrm{RDG}(40 \mathrm{~nm})$ and $\mathrm{RDG}(70 \mathrm{~nm})$ compared with Mie resulted from the larger initial difference between the

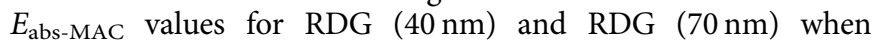
$k_{\mathrm{BrC}}=0$. 


\begin{tabular}{|l}
- Observed \\
$-k_{\mathrm{BrC}}=0$ \\
$k_{\mathrm{BrC}}=0.002--k_{\mathrm{BrC}, \mathrm{ext}}=0.008, k_{\mathrm{BrC}, \mathrm{int}}=0$ \\
$-k_{\mathrm{BrC}}=0.004--k_{\mathrm{BrC}, \mathrm{amb}}=0.004, k_{\mathrm{BrC}, \mathrm{TD}}=0.016$ \\
$-k_{\mathrm{BrC}}=0.008--k_{\mathrm{BrC}, \mathrm{amb}}=0.008, k_{\mathrm{BrC}, \mathrm{TD}}=0.032$ \\
$-k_{\mathrm{BrC}}=0.012--k_{\mathrm{BrC}, \mathrm{amb}}=0.012, k_{\mathrm{BrC}, \mathrm{TD}}=0.048$ \\
\hline
\end{tabular}

a
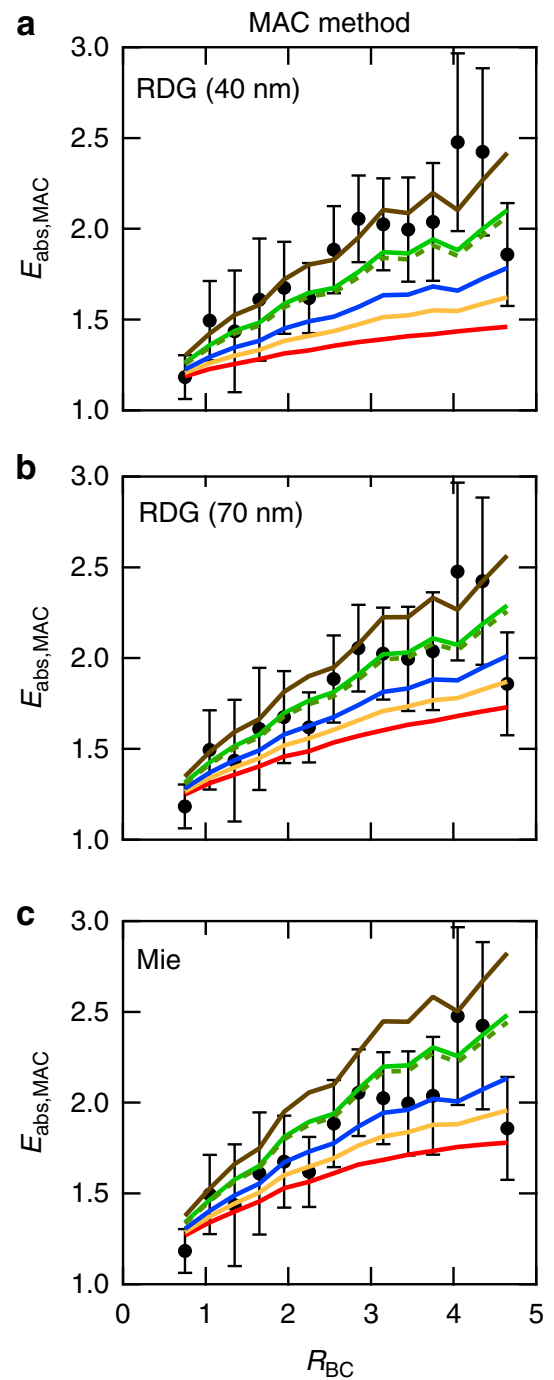
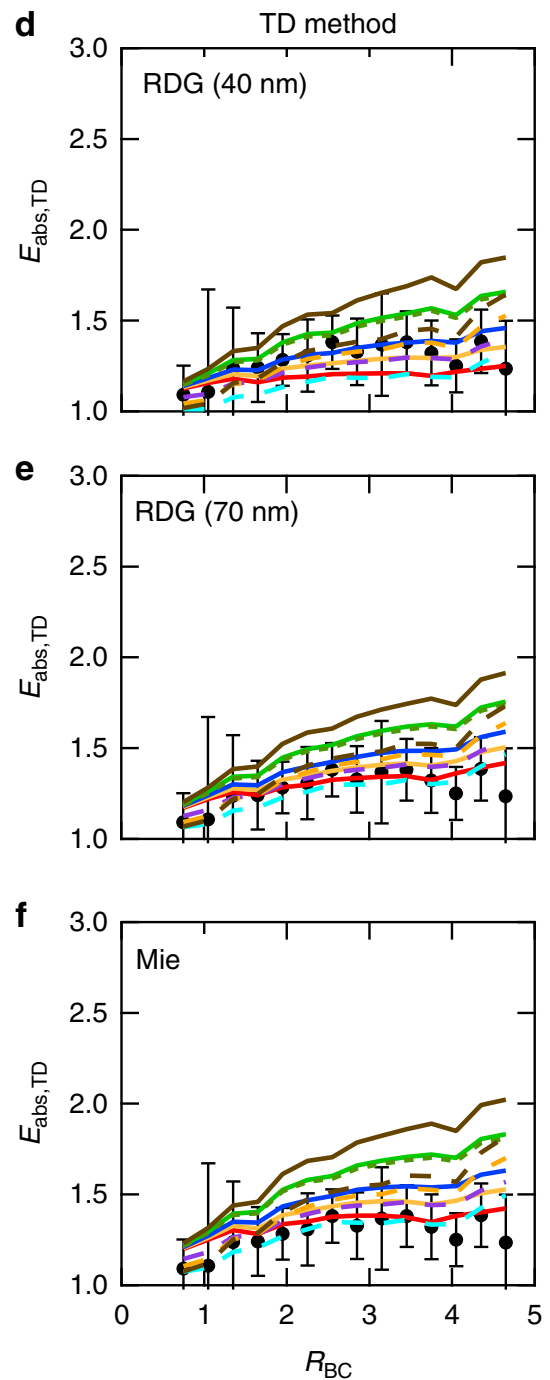

Figure 2 | Comparison of observed and modelled $\boldsymbol{E}_{\mathrm{abs}, \mathbf{M A C}}$ and $\boldsymbol{E}_{\mathrm{abs}, \mathrm{TD}}$ at $\mathbf{4 0 5} \mathbf{n m}$. Mie and RDG calculations (assuming BC spherule sizes of 40 and $70 \mathrm{~nm}$ ) were performed using a range of $k_{\mathrm{BrC}}$ values that are shown in the legend. $k_{\mathrm{BrC}}$ indicates the cases in which a single $k_{\mathrm{BrC}}$ value was assumed for $\mathrm{OM} ; k_{\mathrm{BrC}, \text { ext }}$ and $k_{\mathrm{BrC}, \text { int }}$ represent the $k_{\mathrm{BrC}}$ values for $\mathrm{OM}$ that was externally and internally mixed with $\mathrm{BC}$, respectively; $k_{\mathrm{BrC} \text {,amb }}$ and $k_{\mathrm{BrC}, \mathrm{TD}}$ represent the $k_{\mathrm{BrC}}$ values for ambient and thermodenuded OM, respectively. The error bars in (a-f) represent s.d. of the measured absorption enhancement values for each $R_{\mathrm{BC}}$ interval.

The $E_{\text {abs-TD }}$ at $405 \mathrm{~nm}$ was well-simulated when the OM was assumed non-absorbing, which is inconsistent with the above finding that the OM needed to be absorbing at $405 \mathrm{~nm}$ to match the $E_{\text {abs-MAC }}$ measurements. Alternatively, reasonable quantitative agreement between the observed and calculated $E_{\text {abs-TD }}$ at $405 \mathrm{~nm}$ was obtained when the small amount of residual, low-volatility $\mathrm{OM}$ after thermodenuding was assumed to be more absorbing than the ambient OM. Specifically, good agreement (on average within 5\%) was obtained for the Mie calculation when $k_{\mathrm{BrC}}$ of thermodenuded $\mathrm{OM}\left(k_{\mathrm{BrC}, \mathrm{TD}}\right)$ equals 0.032 at $405 \mathrm{~nm}$, while $k_{\mathrm{BrC}}=0.004$. The $M A C$ calculated for the $\mathrm{BrC}$ scales approximately linearly with $k_{\mathrm{BrC}}$, and thus these results indicate the residual OM was approximately 8 times as absorbing per mass as the ambient OM. This finding indicates that the OM components that evaporated were comparably much less absorbing, with an estimated imaginary refractive index of 0.001 at $405 \mathrm{~nm}$ assuming volume mixing and that the average residual OM was $8.5 \%$ of the total (measured by the HR-ToF-AMS). This result gives a ratio between the $k_{\mathrm{BrC}, \mathrm{TD}}$ and the $k_{\mathrm{BrC}}$ for the evaporated components of $\sim 32$, consistent with the results from the apportionment of $b_{\text {abs }}^{405}$ above. For the RDG calculation, good observation-model agreement can be achieved when the residual $\mathrm{OM}$ was six times as absorbing as the ambient $\mathrm{OM}$, that is, $k_{\mathrm{BrC}, \mathrm{TD}}=0.048$ for $\mathrm{RDG}(70 \mathrm{~nm})$ and $k_{\mathrm{BrC}, \mathrm{TD}}=0.072$ for $\mathrm{RDG}(40 \mathrm{~nm})$. The overall results indicate that there was a non-negligible lensing-driven absorption enhancement of $\mathrm{BC}$ in Detling, and $\mathrm{BrC}$ contributed substantially to the observed particle absorption, and thus as well to the observed $E_{\text {abs }}$ at $405 \mathrm{~nm}$. 
a
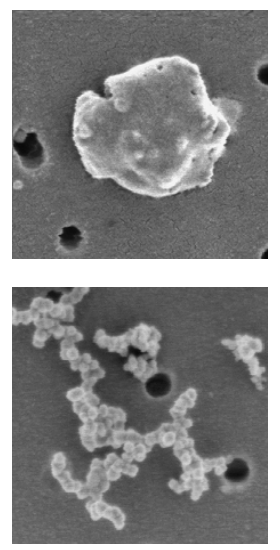
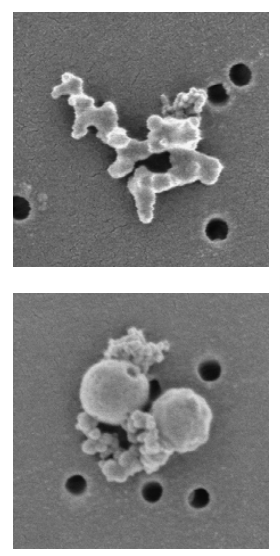

b

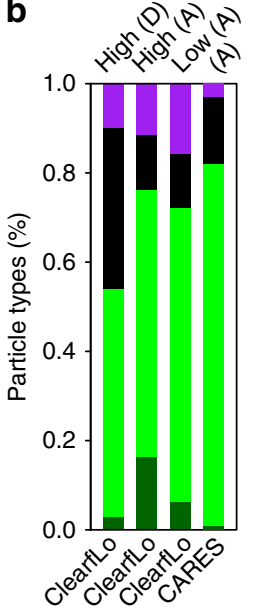

C

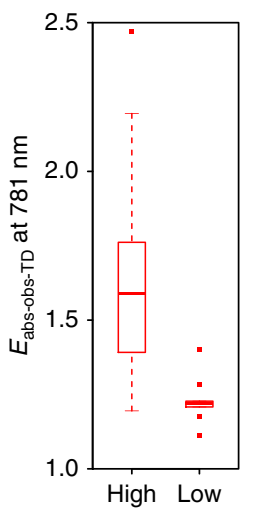

d

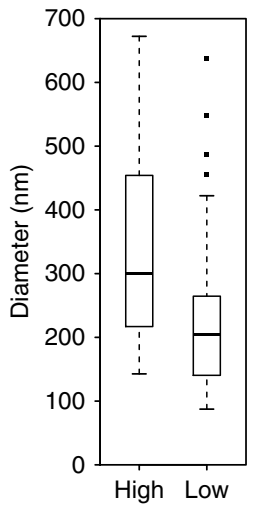

Figure 3 | Morphology and statistics of BC-containing particles. (a) Representative electron microscopy images of BC-containing particles collected at the Detling site for embedded (top left), partly coated (top right), thinly coated (bottom left) and partially encapsulated and/or surface attached (bottom right) BC particle types. The size of each panel is $1 \mu \mathrm{m}$ by $1 \mu \mathrm{m}$. (b) Average number fraction of particle types with the colours indicating embedded (dark green), partly coated (green), thinly coated (black) and partially encapsulated and/or surface attached (purple) BC particle types for the high- and

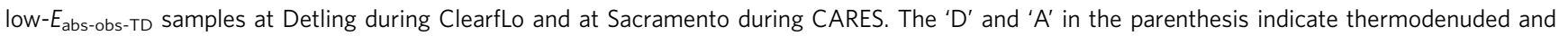

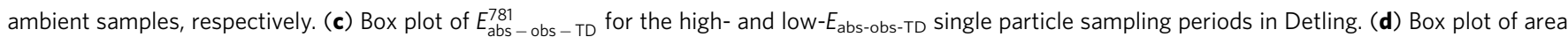
equivalent diameter of the embedded BC particles for the high- $E_{\text {abs-obs-TD }}$ samples (\#1 and \#2 in Supplementary Table 3) and low- $E_{\text {abs-obs-TD samples }}$ (\#3 and \#4 in Supplementary Table 3) for the Detling measurements. In the box plots (c,d), the bounds of each box represent quartiles, and the whiskers extend to the most extreme data points that are within 1.5 interquartile range of the box. The horizontal bars inside the boxes represent the median values.

Mechanistic insight of $E_{\text {abs }}$ from particle morphology. To develop a mechanistic understanding of the notable dependence of $E_{\mathrm{abs}}$ on $R_{\mathrm{BC}}$ at Detling, single-particle images from scanning electron microscopy were analysed. Individual BC particles were classified visually based on their coating and morphologies as 'embedded', 'partly coated', 'thinly coated', and 'partially encapsulated and/or surface attached' (Fig. 3a), similarly to China et al. ${ }^{41,42}$ The number fraction of each type was determined (Supplementary Table 3) and the averages are shown in Fig. 3b. (The electron microscopy analysis may exhibit some composition-dependent biases due to possible losses of semivolatile materials; Methods.)

Two samples were selected for analysis when the $E_{\text {abs-obs-TD }}$ at $781 \mathrm{~nm}$ was high and another two samples were selected during low- $E_{\text {abs-obs-TD }}$ periods. The $E_{\text {abs - obs - TD }}^{781}$ values for the high- and low- $E_{\text {abs-obs-TD }}$ samples were $1.67 \pm 0.42$ (s.d.) and $1.23 \pm 0.07$ (s.d.), respectively (Fig. 3c). The embedded, partly coated, thinly coated and partially encapsulated and/or surface attached particle types had number fractions of $17 \%, 60 \%, 12 \%$ and $11 \%$ (out of 2187 particles) for the high- $E_{\text {abs-obs-TD }}$ and 6\%, 66\%, $12 \%$ and $16 \%$ (out of 2017 particles) for the low- $E_{\text {abs-obs-TD }}$ samples. Therefore, the largest difference between the high- and low- $E_{\text {abs-obs-TD }}$ samples was that the high- $E_{\text {abs-obs-TD }}$ samples contained $\sim 3$ times more embedded $\mathrm{BC}$ particles. The morphological configuration of embedded $\mathrm{BC}$ particles is closest to the core-shell structure commonly used in models and it is theoretically expected to show the largest absorption enhancement. In addition, the embedded particles for the high- $E_{\text {abs-obs-TD }}$ samples had significantly larger area equivalent diameter than those for the low- $E_{\text {abs-obs-TD }}$ samples (Fig. $3 \mathrm{~d}$ ) with the difference ranging between 58 and $159 \mathrm{~nm}$ at the $95 \%$ confidence level, suggesting that the $\mathrm{BC}$ particles associated with high- $E_{\text {abs-obs-TD }}$ underwent substantial coating. Moreover, the thermodenuded particles during the high- $E_{\text {abs-obs-TD }}$ period (Supplementary Table 3) showed a substantially larger fraction (36\%) of thinly coated BC particles and a smaller fraction (3\%) of embedded BC particles compared with the simultaneously collected ambient sample (Fig. 3b), consistent with the presence of semi-volatile components in the coatings on BC particles.

A similar analysis for particles collected at the urban T0 site (14 km northeast of the Sacramento downtown, CA, USA) during the Carbonaceous Aerosols and Radiative Effects Study (CARES) campaign is also shown in Supplementary Table 3 and the fractions of each type are shown in Fig. 3b. The embedded fraction was substantially higher at Detling (12\%) than in Sacramento during the CARES campaign (1\%), where only small $E_{\text {abs }}$ is observed even at relatively large photochemical age (up to $\sim 15 \mathrm{~h})^{14}$. In addition, the convexity ${ }^{42}$, which is associated with the compactness of the BC-containing particles, was higher for Detling $(0.82 \pm 0.005)$ than CARES $(0.76 \pm 0.005)$, suggesting different particle morphology at the two sites. This result indicates that mixing state may play an important role in determining $E_{\text {abs. }}$. However, comparable electron microscopy measurements are not available for the CalNex campaign ${ }^{14}$, where small $E_{\mathrm{abs}}$ values are observed even though similar SP-AMS measurements show substantially larger $R_{\mathrm{BC}}$ compared to the Detling measurements. Therefore, the hypothesis that the morphological details of the internal mixing-state significantly influence the absorption enhancement needs additional evidence with further field studies covering a range of different environments.

\section{Discussion}

Our field results demonstrate clearly that coatings can substantially enhance light absorption by $\mathrm{BC}$ emitted from mixed fossil fuel and residential solid fuel combustion sources. Photochemical aging can play an important role in BC's absorption enhancement by coating $\mathrm{BC}$ particles with condensable materials. Comparison with results from other field campaigns indicates that the influence of coatings on $\mathrm{BC}$ absorption may be source and regionally specific. We hypothesize that mixed combustion sources and atmospheric transformations can produce favourable conditions of enhanced BC absorption by coatings, including 
BrC. Our analysis of absorption enhancement as a function of morphology, mixing state, coating thickness and the amount of low-volatility and semi-volatile $\mathrm{BrC}$ at wintertime Detling supports our hypothesis. We highlight that the effects of $\mathrm{BrC}$, in particular the low-volatility $\mathrm{BrC}$, on $\mathrm{BC}$ 's absorption enhancement at short wavelengths should be considered in future studies. Our findings should be evaluated by future measurements of atmospherically processed $\mathrm{BC}$ particles from mixed combustion sources at other locations. We recommend that models treat the variability of $\mathrm{BC}$ 's absorption to account for the dynamic aging processes and regional variations in sources by calibrating Mie models to measurements. Continued assessment of the absorption enhancement by $\mathrm{BC}$ coatings (including $\mathrm{BrC}$ ) through comparing observations and observationally constrained calculations is necessary to develop robust numerical models, in order to accurately quantify the past, present and future contributions of absorbing particles to climate change.

\section{Methods}

Thermodenuder. A thermodenuder (TD, Aerodyne Research, Inc., Billerica, MA, USA) was installed upstream of all the instruments used in this study to evaporate semi-volatile particulate components. The flowrate through the TD was 2.3 l.p.m., resulting in a residence time of $5.3 \mathrm{~s}$, which was shorter than the $8.5 \mathrm{~s}$ residence time in the study by Cappa et al. ${ }^{14}$

Ambient particles and heated particles were alternately sampled during 5-15 February 2012 with TD temperatures of 120 and $250^{\circ} \mathrm{C}$. Each ambient-TD cycle included 10-min ambient measurements and 10-min TD measurements. Unless stated otherwise, the $E_{\mathrm{abs}}$ values derived from $250^{\circ} \mathrm{C}$ thermodenuding were reported.

Photoacoustic soot spectrometer. A three-wavelength photoacoustic soot spectrometer (PASS-3, Droplet Measurement Technologies, Inc., Boulder, CO, USA) was used to continuously measure the absorption and scattering coefficients of fine particles at 405,532 and $781 \mathrm{~nm}$. In the PASS-3, the particle laden sample is illuminated with a modulated laser. The energy absorbed from the incident light is thermally transferred to the air surrounding the particle and the subsequent air expansion produces a sound wave ${ }^{26}$. The sound wave is measured by a microphone that was calibrated at $532 \mathrm{~nm}$ at Droplet Measurement Technologies, Inc. using $\mathrm{NO}_{2}$ (ref. 43). The microphone calibration is independent of wavelength and the lasers at 405, 532 and $781 \mathrm{~nm}$ were calibrated using a laser power meter. The calibration was checked using size selected fullerene soot particles (Alpha Aesar, Ward Hill, Massachusetts) following the procedures described by Flowers et al. ${ }^{44}$ An $\mathrm{NO}_{2}$ scrubber was installed upstream of the PASS-3 to remove the interference of $\mathrm{NO}_{2}$ absorption at $405 \mathrm{~nm}$. Background measurements of filtered air were made every $2.5 \mathrm{~min}$ to allow for correction of changes in gas composition. During the Detling measurements, low $532 \mathrm{~nm}$ laser power and drifts caused large variations of the signal in this channel. Therefore, $b_{\mathrm{abs}}^{532}$ was used as a qualitative measurement only and is not included here. Allan variance plots were made before the measurements to evaluate the precision and stability of the performance of the PASS-3 (refs 45,46). The precision at $2.5 \mathrm{~min}$ integration time was $0.5 \mathrm{M} \mathrm{m}^{-1}$ for $b_{\text {abs }}^{405}$ and $0.3 \mathrm{M} \mathrm{m}^{-1}$ for $b_{\text {abs }}^{781}$. Zero tests using high-efficiency particulate arrestance filters suggested that the gas-phase absorption was within the precision of the PASS-3 measurements. The upper limit of the gas-phase contribution to absorption was estimated to be 4 and $6 \%$ at 405 and $781 \mathrm{~nm}$, respectively. The relative humidity inside the PASS-3 instrument was smaller than $30 \%$, suggesting that the particles were dry by the time they were measured. The low relative humidity inside the PASS- 3 instrument was due to warm up of the cold air brought into the warmer container and the relatively high temperature $\left(20-30{ }^{\circ} \mathrm{C}\right)$ in the PASS- 3 measurement cell induced by the electronics.

To verify the PASS-3 measurements, the absorption measured by the PASS-3 was compared with the absorption calculated from a 7-wavelength Aethalometer (MAGEE Scientific, model AE31) that operated simultaneously at the same site ${ }^{47}$. The PASS-3 measured absorption correlated well with the Aethalometer-derived absorption with Pearson's $r \geq 0.94$ at 405 and $781 \mathrm{~nm}$. Major axis line-fitting suggests that the PASS- 3 and Aethalometer measurements agreed well, with slopes close to $1(0.934 \pm 0.004$ at 405 and $0.918 \pm 0.004$ at $781 \mathrm{~nm})$ and intercepts slightly negative $\left(-2.724 \pm 0.085\right.$ and $\left.-1.847 \pm 0.037 \mathrm{M} \mathrm{m}^{-1}\right)$.

SP2. The refractory BC $(\mathrm{rBC})$ mass concentration was quantified using an SP2 (Droplet Measurement Technologies, Inc., Boulder, CO, USA). Measurement principles of the SP2 have been described in detail in previous publications ${ }^{27,28}$. In brief, the SP2 selectively measures the $\mathrm{rBC}$-containing particles using a diodepumped $1064 \mathrm{~nm}$ Nd:YAG laser on a single-particle basis. The rBC-containing particles absorb the energy emitted by the laser and are heated to their vaporization temperature and incandesce. The peak intensity of the incandescence signal is proportional to the mass of $\mathrm{rBC}$, allowing for the quantification of $\mathrm{rBC}$ mass concentration. The SP2 measures single $\mathrm{rBC}$-containing particles with an $\mathrm{rBC}$ mass range of $\sim 3-300 \mathrm{fg}$ (ref. 27). The size of the $\mathrm{rBC}$ was calculated assuming a density of $1.8 \mathrm{~g} \mathrm{~cm}^{-3}$ and assuming spherical geometry with no internal voids ${ }^{48}$. Size-selected fullerene soot (Alfa Aesar, Ward Hill, Massachusetts; Stock\# 40971, Lot\# L18U002) was used for the SP2 mass calibration ${ }^{49}$. Contributions of rBC particles outside the detection window-which can vary with $\mathrm{rBC}$ source-were quantitatively estimated by fitting time-dependent $\mathrm{rBC}$ size distributions assuming a bimodal lognormal shape. The good correlation between absorption and $[\mathrm{rBC}]$ (Supplementary Fig. 4) suggests that the lognormal correction was sufficient to account for the rBC mass outside the SP2 detection limit.

HR-ToF-AMS. An Aerodyne HR-ToF-AMS (Aerodyne, Research Inc., Billerica, MA, USA) was deployed to measure the non-refractory organics, sulfate, nitrate, ammonium and chloride in submicron particles with 2-min time resolution. The HR-ToF-AMS configuration and principle of operation have been described in detail previously 29,30 . Briefly, particles that are focused and accelerated by an aerodynamic lens impact a heated vaporizer $\left(600^{\circ} \mathrm{C}\right)$. The non-refractory components in the particles are flash vapourized and ionized, and the ionized fragments are measured by a high-resolution time-of-flight mass spectrometer.

SP-AMS. The SP-AMS (Aerodyne Research, Inc., Billerica, MA, USA) incorporates a $1064 \mathrm{~nm}$ Nd:YAG laser vaporizer (the same laser as used in the SP2 instrument) into the standard Aerodyne HR-ToF-AMS to detect $\mathrm{rBC}$ via laserinduced heating and vaporization ${ }^{31}$. During $5-15$ February 2012, the tungsten thermal vaporizer was removed from the SP-AMS so that only $\mathrm{rBC}$ and the $\mathrm{rBC}-$ associated non-refractory particulate matter (including organics, sulfate, nitrate, ammonium and chloride) were detected. By comparing the ambient and thermodenuded $\mathrm{OM}$ that was associated with $\mathrm{BC}$ (normalized to [rBC] to account for particle losses in the heated TD), we find that on average $24 \%$ of OM that was internally mixed with $\mathrm{rBC}$ remained associated with the $\mathrm{rBC}$ particles after heating to $250^{\circ} \mathrm{C}$. This result is consistent with a previous study ${ }^{50}$ that shows large contribution $(\sim 11 \%)$ of organic components to particulate residuals after particle heating at $300^{\circ} \mathrm{C}$.

Electron microscopy analysis. Single particles were collected on Nuclepore filters (100 $\mathrm{nm}$ pores) using an aspiration sampling technique. The sample collection time was 3-6 h depending on the particle concentration. For each collection time period, two filter samples, one representing ambient and the other representing heated (at $120^{\circ} \mathrm{C}$ through a TD) particles, were collected simultaneously. This TD was different from the TD used for the PASS-3, HR-ToF-AMS and SP-AMS, and therefore it may remove a different amount of material. After collection, the samples were stored in the dark before analysis. The particle images were acquired using a field emission scanning electron microscope (Hitachi S-4700). We note that only particles larger than $100 \mathrm{~nm}$ were analysed to reduce uncertainties in particle classification. In addition, the number of embedded BC-containing particles was likely underestimated because (1) electron microscopy images only the surface features of the particles, thereby the BC-containing particles that were entirely engulfed by other materials and completely lost their original BC morphology could not be identified and (2) the electron microscopy analysis was conducted under vacuum, so evaporation of semi-volatile coatings on BC particles could not be avoided. Therefore, the number fraction for each particle type derived from the electron microscopy analysis was semi-quantitative.

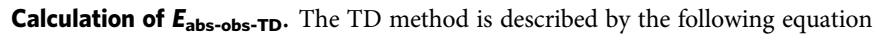

$$
E_{\text {abs }- \text { obs }-\mathrm{TD}}^{\lambda}=\frac{\left(b_{\mathrm{abs}, \mathrm{amb}}^{\lambda}(t-1) /[\mathrm{rBC}](t-1)+b_{\mathrm{abs}, \mathrm{amb}}^{\lambda}(t+1) /[\mathrm{rBC}](t+1)\right) / 2}{b_{\mathrm{abs}, \mathrm{TD}}^{\lambda}(t) /[\mathrm{rBC}](t)}
$$

where $b_{\mathrm{abs}, \mathrm{amb}}^{\lambda}$ and $b_{\mathrm{abs}, \mathrm{TD}}^{\lambda}$ represent the absorption coefficients of ambient and thermodenuded particles, respectively; $[\mathrm{rBC}]$ is the mass concentration of $\mathrm{rBC}$ measured by the SP2; $t$ represents the TD measurement, and $t-1$ and $t+1$ represent the times corresponding to ambient measurements before and after the TD measurement, respectively. Over $95 \%$ of the $E_{\text {abs-obs-TD values were }>1 \text {, with }}$ the values smaller than 1 resulting from temporal atmospheric variability during the sequential ambient and TD measurements.

Calculation of $\boldsymbol{E}_{\text {abs-obs-MAC. }}$ In the calculation of $E_{\text {abs-obs-MAC, }}$ the measurements were binned by the $R_{\mathrm{BC}}$ intervals, and the $M A C$ of $\mathrm{BC}$ was determined as the slope of the line-fitting of $b_{\mathrm{abs}}^{\lambda}$ as a function of $[\mathrm{rBC}]$ for each measurement section (Supplementary Fig. 4). We examined the linear regression, major axis (also called orthogonal regression), and standardized major axis (also called reduced major axis) least square line-fitting methods. The linear regression method only accounts for the errors in the $Y$ direction, while the other two methods take into account errors in both $X$ and $Y$ directions. The standardized major axis is the major axis calculated on standardized data. The standardized major axis is typically used when 
$X$ and $Y$ data are not measured on comparable scales ${ }^{51}$, which is appropriate for the $b_{\text {abs }}$ versus $[\mathrm{rBC}]$ line-fitting in this study. In addition, comparison of the three fitting methods results showed that the slopes derived from standardized major axis were in between those derived from the linear regression and major axis fitting methods (Supplementary Fig. 2). An additional method was to take the average point-to-point $b_{\text {abs }} /[\mathrm{rBC}]$ as the $M A C$ value for each $R_{\mathrm{BC}}$ interval, defined as the 'ratio method.' The ratio method did not give the same results as those derived from the slope methods. We suspect that this difference was due to a systematic offset in the PASS-3 measurements that affected the ratio method but not the slope methods. For these reasons, we used the slopes derived from the standardized major axis fitting as the $M A C$ values in this study. $E_{\text {abs-obs-MAC }}$ was calculated as the ratio of the calculated MAC to the reference MAC of uncoated BC.

Apportionment of the absorption at $\mathbf{4 0 5} \mathbf{n m}$. The measured $b_{\mathrm{abs}}^{405}$ was the sum of the absorption of $\mathrm{BC}, \mathrm{BrC}$ (both internally and externally mixed with $\mathrm{BC}$ ), and the enhanced absorption due to the lensing effect of coatings on BC. Upon heating at $250^{\circ} \mathrm{C}$, the semi-volatile $\mathrm{OM}$ and semi-volatile inorganic species evaporated, leaving only $\mathrm{BC}$ and low-volatility non-BC materials. Unless stated otherwise, the temperature threshold for separating semi-volatile and low-volatility components was defined as $250^{\circ} \mathrm{C}$ in this study. $b_{\text {abs }}^{405}$ can be apportioned using $b_{\text {abs.amb }}^{405}$ and $b_{\text {abs,TD }}^{405}\left(\right.$ at $250^{\circ} \mathrm{C}$ ) based on the following assumptions: (1) BrC absorbs at $405 \mathrm{~nm}$ but not at $781 \mathrm{~nm}$ (ref. 24); (2) the absorption of the residual BC particles (after heating) follows the inverse wavelength dependence; and (3) to a first-order approximation the lensing-driven enhancement for $\mathrm{BC}$ particles is wavelength independent, that is, $E_{\mathrm{abs}}^{405}\left(\right.$ Lens $\left._{\mathrm{SV}}\right)=E_{\mathrm{abs}}^{781}\left(\right.$ Lens $\left._{\mathrm{SV}}\right)$ for the same BC-containing particle ${ }^{52}$. Note that the measured ambient $E_{\text {abs }- \text { obs }-T D}$ included the lensingdriven enhancement and the enhancement induced by evaporation of $\mathrm{BrC}_{\mathrm{SV}}$, and further $E_{\text {abs - obs - TD }}^{405}$ was affected by $\mathrm{BrC}_{\mathrm{LV}}$ as discussed in the main text. Therefore $E_{\text {abs }}^{405}$ - obs - TD is different from $E_{\text {abs }}^{405}\left(\right.$ Lens $\left._{\mathrm{SV}}\right)$ used in the equations below: $E_{\text {abs }}^{405}$ (Lenssv) excludes the effects of $\mathrm{BrC}\left(\mathrm{BrC}_{\mathrm{LV}}\right.$ and $\left.\mathrm{BrC}_{\mathrm{SV}}\right)$ and represents the lensing-driven enhancement only. In comparison with $E_{\text {abs - obs-TD }}^{405}$, the measured $E_{\text {abs }- \text { obs }-\mathrm{TD}}^{78}$ was due to the lensing-driven enhancement only, that is, $E_{\mathrm{abs}-\mathrm{obs}-\mathrm{TD}}^{781}=E_{\mathrm{abs}}^{781}\left(\right.$ Lens $\left._{\mathrm{sV}}\right)$. The apportionment is described by the following equations with the variables described in Supplementary Table 1:

$$
\begin{gathered}
b_{\mathrm{abs}}^{405}\left(\mathrm{~T}_{250}\right)=b_{\mathrm{abs}}^{405}\left(\mathrm{BC}_{\text {residual }}\right)+b_{\mathrm{abs}}^{405}\left(\mathrm{BrC}_{\mathrm{LV}}\right) \\
b_{\mathrm{abs}}^{781}\left(\mathrm{~T}_{250}\right)=b_{\mathrm{abs}}^{781}\left(\mathrm{BC}_{\text {residual }}\right) \\
\frac{b_{\mathrm{abs}}^{405}\left(\mathrm{BC}_{\text {residual }}\right)}{b_{\mathrm{abs}}^{781}\left(\mathrm{BC}_{\text {residual }}\right)}=\left(\frac{405}{781}\right)^{-1} \\
b_{\mathrm{abs}}^{405}\left(\mathrm{~T}_{\mathrm{amb}}\right)=b_{\mathrm{abs}}^{405}\left(\mathrm{BC}_{\text {residual }}\right) \cdot E_{\mathrm{abs}}^{405}\left(\text { Lens }_{\mathrm{SV}}\right)+b_{\mathrm{abs}}^{405}\left(\mathrm{BrC}_{\mathrm{LV}}\right)+b_{\mathrm{abs}}^{405}\left(\mathrm{BrC}_{\mathrm{SV}}\right) \\
E_{\mathrm{abs}}^{405}\left(\text { Lens }_{\mathrm{SV}}\right)=E_{\mathrm{abs}}^{781}\left(\text { Lens }_{\mathrm{SV}}\right)=E_{\mathrm{abs}-\text { obs }-\mathrm{TD}}^{781}
\end{gathered}
$$

From equations $(2-4), b_{\mathrm{abs}}^{405}\left(\mathrm{BrC}_{\mathrm{LV}}\right)$ and $b_{\mathrm{abs}}^{405}\left(\mathrm{BC}_{\text {residual }}\right)$ were solved; $b_{\mathrm{abs}}^{405}\left(\mathrm{BrC}_{\mathrm{SV}}\right)$ was then derived using equations (5) and (6).

Similar apportionment of $b_{\mathrm{abs}}^{405}$ was performed using the $b_{\mathrm{abs}}^{405}$ for particles that were thermodenuded at $120^{\circ} \mathrm{C}$. In this case, the $\mathrm{BrC}_{\mathrm{LV}}$ was referred to as the fraction of $\mathrm{BrC}$ that remained in the particles after thermodenuding at $120^{\circ} \mathrm{C}$. The apportioned $b_{\text {abs }}^{405}\left(\mathrm{BrC}_{\mathrm{LV}}\right)$ at $120^{\circ} \mathrm{C}$ and $250^{\circ} \mathrm{C}$ correlated in time with a Pearson's $r$ of 0.8 , and the latter was $19 \%$ lower on average, which was likely because of the absorption of $\mathrm{BrC}$ that evaporated between 120 and $250^{\circ} \mathrm{C}$. Since charring of $\mathrm{OM}$ is unlikely to take place at $120^{\circ} \mathrm{C}$, the correlation of apportioned $b_{\mathrm{abs}}^{405}\left(\mathrm{BrC}_{\mathrm{LV}}\right)$ at 120 and $250^{\circ} \mathrm{C}$ suggests that $b_{\mathrm{abs}}^{405}\left(\mathrm{BrC}_{\mathrm{LV}}\right)$ at $250^{\circ} \mathrm{C}$ was a real signal rather than an artefact resulting from pyrolyzed OM. This result is consistent with previous studies that confirm that the interference of pyrolyzed OM on the absorption measurements is $<1.7 \%$ at $300^{\circ} \mathrm{C}$ (ref. 53).

Non-fossil fractions of oxygenated organic carbon. Radiocarbon $\left({ }^{14} \mathrm{C}\right)$ analysis was used to distinguish the fossil and non-fossil carbon fractions of the oxygenated organic aerosols retrieved from the HR-ToF-AMS analysis. Non-fossil carbon fraction $\left(f_{\mathrm{NF}}\right)$ was calculated as the ratio of ${ }^{14} \mathrm{C} /{ }^{12} \mathrm{C}$ for the sample to ${ }^{14} \mathrm{C} /{ }^{12} \mathrm{C}$ in 1950 after correcting for field blanks and nuclear weapon tests in the 1950s and 1960 s (ref. 54). The $f_{\mathrm{NF}}$ for total carbon $\left(f_{\mathrm{NF}, \mathrm{TC}}\right)$ in Detling has been reported by Crilley et al. ${ }^{55}$, in which the total carbon is the sum of organic carbon and elemental carbon measured with a Sunset thermal-optical carbon analyser. $f_{\mathrm{NF}}$ of $\mathrm{BC}\left(f_{\mathrm{NF}, \mathrm{BC}}\right)$ in Detling was assumed to be the wood burning fraction of $\mathrm{BC}$, apportioned using the Aethalometer measurements and a source apportionment model ${ }^{56}$ as reported in Crilley et al. The average $f_{\mathrm{NF}, \mathrm{TC}}$ and $f_{\mathrm{NF}, \mathrm{BC}}$ at Detling during ClearfLo are $64 \pm 7 \%$ and $30 \pm 13 \%$ (ref. 55), respectively.

Here, we expanded the Crilley et al. analysis to analyse the $f_{\mathrm{NF}}$ for oxygenated organic aerosols using the method described in Zotter et al. ${ }^{54}$ The equation we used for the $f_{\mathrm{NF}}$ calculation is as follows

$$
\begin{aligned}
f_{\mathrm{NF}, \mathrm{OOC}} \times \mathrm{OOC}= & f_{\mathrm{NF}, \mathrm{TC}} \times \mathrm{TC}-f_{\mathrm{NF}, \mathrm{BC}} \times \mathrm{rBC}-f_{\mathrm{NF}, \mathrm{HOC}} \times \mathrm{HOC} \\
& -f_{\mathrm{NF}, \mathrm{SFOC}} \times \mathrm{SFOC}
\end{aligned}
$$

where HOC, SFOC and OOC are the organic carbon concentrations for hydrocarbon-like organic aerosol, solid fuel organic aerosol, and oxygenated organic aerosol factors, respectively. The organic carbon concentration of the factor was converted from the corresponding factor OM concentration, using the OM to organic carbon ratios derived from the factor spectra. $\mathrm{rBC}$ is the ambient refractory $\mathrm{BC}$ concentration measured by the SP2. TC is the total carbon concentration, equivalent to the sum of HOC, SFOC, OOC, and BC concentrations. $f_{\mathrm{NF}, \mathrm{TC}}$ and $f_{\mathrm{NF}, \mathrm{BC}}$ values are the same as reported in Crilley et al. ${ }^{55}$ We used the $f_{\mathrm{NF}, \mathrm{TC}}$ and $f_{\mathrm{NF}, \mathrm{BC}}$ values for 5-12 February 2012 that overlapped the $E_{\mathrm{abs}}$ measurements. $f_{\mathrm{NF}, \mathrm{HOC}}$ and $f_{\mathrm{NF}, \mathrm{SFOC}}$ are the non-fossil carbon fractions for HOC and SOFC, respectively. Since $f_{\mathrm{NF}, \mathrm{HOC}}$ and $f_{\mathrm{NF}, \mathrm{SFOC}}$ were not explicitly known, we performed sensitivity analysis using a pseudo Monte Carlo method. In this method, $f_{\mathrm{NF}, \mathrm{HOC}}$ was varied between 0 and 0.3 , representing its substantial fossil emissions and accounting for the potential contribution of non-fossil cooking and biofuel combustion (for example, biodiesel) emissions that were not separated from HOC; $f_{\mathrm{NF}, \mathrm{SFOC}}$ was varied between 0.9 and 1.0 to consider the dominance of wood burning and account for the contribution of residential (fossil) coal burning to SFOC.

The apportionment result (Supplementary Fig. 5) showed that the $f_{\mathrm{NF}, \mathrm{OOC}}$ ranged from 0.75 to 0.93 , suggesting that the majority of oxygenated organic aerosols was from non-fossil sources in Detling during ClearfLo.

Mie and RDG model calculations. The Mie calculations were performed using the same Igor code (Wavemetrics Inc) as in Cappa et al. ${ }^{14}$, which was adapted from the Fortran code of Bohren and Huffman ${ }^{57}$. The input size distributions for the calculation were constrained by observations using the same set of measurements (from the same types of instruments) and methods as detailed in Cappa et al., that is, the core $\mathrm{BC}$ size distribution was constrained by the SP2 measurements, the coated $\mathrm{BC}$-containing particle size distribution was determined by $R_{\mathrm{BC}}$ and the core $\mathrm{BC}$ size distribution assuming that the coated components were evenly distributed around $\mathrm{BC}$ particles, and the non- $\mathrm{BC}$ particle size distribution was derived by subtracting the SP2-measured BC size distribution from the total particle size distribution measured by a scanning mobility particle sizer.

In the RDG calculation, the number of spherules per particle was calculated by the assumed spherule size and the SP2-measured spherical equivalent volumes of the overall $\mathrm{BC}$ core. It was assumed that the amount of coating on each spherule was proportionally the same as for the total particle, that is, that $R_{\mathrm{BC}}$ was the same for the spherule as for the total particle. This assumption is equivalent to having the ratio between the coated diameter and the core diameter conserved between the standard Mie (total particle) formulation and the RDG formulation. The absorption enhancements for the RDG cases were calculated analogously to the Mie case.

The refractive index of $\mathrm{BC}$ was assumed to be $n=1.88+0.8 i$ (ref. 14). Since the imaginary refractive index of $\mathrm{BrC}\left(k_{\mathrm{BrC}}\right)$ is highly uncertain and can vary greatly, we performed calculations to estimate the $k_{\mathrm{BrC}}$ that resulted in good agreement between predicted and measured $E_{\text {abs-MAC }}$ and $E_{\text {abs-TD }}$ at $405 \mathrm{~nm}$. It was assumed that the refractive index was a bulk average for OM.

\section{References}

1. Ramanathan, V. \& Carmichael, G. Global and regional climate changes due to black carbon. Nat. Geosci. 1, 221-227 (2008).

2. Andreae, M. O. \& Gelencsér, A. Black carbon or brown carbon? The nature of light-absorbing carbonaceous aerosols. Atmos. Chem. Phys. 6, 3131-3148 (2006).

3. Bond, T. et al. Bounding the role of black carbon in the climate system: a scientific assessment. J. Geophys. Res. 118, 5380-5552 (2013).

4. Feng, Y., Ramanathan, V. \& Kotamarthi, V. Brown carbon: a significant atmospheric absorber of solar radiation? Atmos. Chem. Phys. 13, 8607-8621 (2013).

5. Kirchstetter, T. W. \& Novakov, T. Evidence that the spectral dependence of light absorption by aerosols is affected by organic carbon. J. Geophys. Res. 109, D21208 (2004)

6. Bond, T. C. \& Bergstrom, R. W. Light absorption by carbonaceous particles: an investigative review. Aerosol Sci. Technol. 40, 27-67 (2006).

7. Moffet, R. C. \& Prather, K. A. In-situ measurements of the mixing state and optical properties of soot with implications for radiative forcing estimates. Proc. Natl Acad. Sci. USA 106, 11872-11877 (2009).

8. Fuller, K. A., Malm, W. C. \& Kreidenweis, S. M. Effects of mixing on extinction by carbonaceous particles. J. Geophys. Res. 104, 15941-15954 (1999).

9. Jacobson, M. Z. Strong radiative heating due to the mixing state of black carbon in atmospheric aerosols. Nature 409, 695-697 (2001).

10. Bond, T. C., Habib, G. \& Bergstrom, R. W. Limitations in the enhancement of visible light absorption due to mixing state. J. Geophys. Res. 111, D20211 (2006).

11. Schwarz, J. et al. Coatings and their enhancement of black carbon light absorption in the tropical atmosphere. J. Geophys. Res. 113, D03203 (2008).

12. Cross, E. S. et al. Soot particle studies-instrument inter-comparison-project overview. Aerosol Sci. Technol 44, 592-611 (2010). 
13. Schnaiter, M. et al. Absorption amplification of black carbon internally mixed with secondary organic aerosol. J. Geophys. Res. 110, D19204 (2005).

14. Cappa, C. D. et al. Radiative absorption enhancements due to the mixing state of atmospheric black carbon. Science 337, 1078-1081 (2012).

15. Shiraiwa, M., Kondo, Y., Iwamoto, T. \& Kita, K. Amplification of light absorption of black carbon by organic coating. Aerosol Sci. Technol. 44, 46-54 (2010).

16. Zhang, R. et al. Variability in morphology, hygroscopicity, and optical properties of soot aerosols during atmospheric processing. Proc. Natl Acad. Sci. USA 105, 10291-10296 (2008)

17. Chung, S. H. \& Seinfeld, J. H. Climate response of direct radiative forcing of anthropogenic black carbon. J. Geophys. Res. 110, D11102 (2005).

18. Penner, J. E., C. Chuang, C. C. \& Grant, K. Climate forcing by carbonaceous and sulfate aerosols. Clim. Dyn. 14, 839-851 (1998).

19. Flanner, M. G., Zender, C. S., Randerson, J. T. \& Rasch, P. J. Present-day climate forcing and response from black carbon in snow. J. Geophys. Res. 112, D11202 (2007).

20. Wang, Q. et al. Global budget and radiative forcing of black carbon aerosol: constraints from pole-to-pole (HIPPO) observations across the Pacific. J. Geophys. Res. 119, 195-206 (2014).

21. Cappa, C. D. et al. Response to comment on 'radiative absorption enhancements due to the mixing state of atmospheric black carbon'. Science 339, 393-393 (2013).

22. Nakayama, T. et al. Properties of light-absorbing aerosols in the Nagoya urban area, Japan, in August 2011 and January 2012: contributions of brown carbon and lensing effect. J. Geophys. Res. 119, 12721-12739 (2014).

23. Adachi, K. \& Buseck, P. R. Changes of ns-soot mixing states and shapes in an urban area during CalNex. J. Geophys. Res. 118, 3723-3730 (2013).

24. Lack, D. A. et al. Brown carbon and internal mixing in biomass burning particles. Proc. Natl Acad. Sci. USA 109, 14802-14807 (2012).

25. Bohnenstengel, S. et al. Meteorology, air quality, and health in London: The ClearfLo project. Bull. Am. Meteor. Soc. 96, 779-804 (2015).

26. Arnott, W. P., Moosmüller, H., Rogers, C. F., Jin, T. F. \& Bruch, R. Photoacoustic spectrometer for measuring light absorption by aerosol: instrument description. Atmos. Environ. 33, 2845-2852 (1999).

27. Schwarz, J. P. et al. Single-particle measurements of midlatitude black carbon and light-scattering aerosols from the boundary layer to the lower stratosphere. J. Geophys. Res. 111, D16207 (2006).

28. Slowik, J. G. et al. An inter-comparison of instruments measuring black carbon content of soot particles. Aerosol Sci. Technol. 41, 295-314 (2007).

29. Canagaratna, M. et al. Chemical and microphysical characterization of ambient aerosols with the Aerodyne aerosol mass spectrometer. Mass Spectrom. Rev. 26, 185-222 (2007).

30. DeCarlo, P. F. et al. Field-deployable, high-resolution, time-of-flight aerosol mass spectrometer. Anal. Chem. 78, 8281-8289 (2006).

31. Onasch, T. B. et al. Soot particle aerosol mass spectrometer: development, validation, and initial application. Aerosol Sci. Technol. 46, 804-817 (2012).

32. Saleh, R. et al. Brownness of organics in aerosols from biomass burning linked to their black carbon content. Nature Geosci. 7, 647-650 (2014).

33. Paatero, P. \& Tapper, U. Positive matrix factorization: A non-negative factor model with optimal utilization of error estimates of data values. Environmetrics 5, 111-126 (1994).

34. Zhang, Q. et al. Understanding atmospheric organic aerosols via factor analysis of aerosol mass spectrometry: a review. Anal. Bioanal. Chem. 401, 3045-3067 (2011).

35. Hoffer, A., Kiss, G., Blazso, M. \& Gelencsér, A. Chemical characterization of humic-like substances (HULIS) formed from a lignin-type precursor in model cloud water. Geophys. Res. Lett. 31, L06115 (2004).

36. Limbeck, A., Kulmala, M. \& Puxbaum, H. Secondary organic aerosol formation in the atmosphere via heterogeneous reaction of gaseous isoprene on acidic particles. Geophys. Res. Lett. 30 (2003).

37. Schwarz, J. P. et al. Measurement of the mixing state, mass, and optical size of individual black carbon particles in urban and biomass burning emissions. Geophys. Res. Lett. 35, L13810 (2008).

38. Kroll, J. H. et al. Carbon oxidation state as a metric for describing the chemistry of atmospheric organic aerosol. Nature Chem. 3, 133-139 (2011).

39. Canagaratna, M. R. et al. Elemental ratio measurements of organic compounds using aerosol mass spectrometry: characterization, improved calibration, and implications. Atmos. Chem. Phys. 15, 253-272 (2015).

40. Liu, D. et al. The effect of complex black carbon microphysics on the determination of the optical properties of brown carbon. Geophys. Res. Lett. 42, 613-619 (2015)

41. China, S., Mazzoleni, C., Gorkowski, K., Aiken, A. C. \& Dubey, M. K. Morphology and mixing state of individual freshly emitted wildfire carbonaceous particles. Nat. Commun. 4, 2122 (2013).
42. China, S. et al. Morphology and mixing state of aged soot particles at a remote marine free troposphere site: implications for optical properties. Geophys. Res. Lett. 42, 1243-1250 (2015).

43. Arnott, W. P., Moosmüller, H. \& Walker, J. W. Nitrogen dioxide and keroseneflame soot calibration of photoacoustic instruments for measurement of light absorption by aerosols. Rev. Sci. Instrum. 71, 4545-4552 (2000).

44. Flowers, B. A. et al. Optical-chemical-microphysical relationships and closure studies for mixed carbonaceous aerosols observed at Jeju Island; 3-laser photoacoustic spectrometer, particle sizing, and filter analysis. Atmos. Chem. Phys. 10, 10387-10398 (2010).

45. Flowers, B. A., Powers, H. H., Dubey, M. K. \& McDowell, N. G. Inter-comparison of two high-accuracy fast-response spectroscopic sensors of carbon dioxide: a case study. Atmos. Meas. Tech. 5, 991-997 (2012).

46. Werle, P., Mucke, R. \& Slemr, F. The limits of signal averaging in atmospheric trace-gas monitoring by tunable diode-laser absorption spectroscopy (TDLAS). Appl. Phys. B 57, 131-139 (1993)

47. Mohr, C. et al. Contribution of nitrated phenols to wood burning brown carbon light absorption in Detling, UK during winter time. Environ. Sci. Technol. 47, 6316-6324 (2013).

48. Moteki, N., Kondo, Y. \& Nakamura, S. Method to measure refractive indices of small nonspherical particles: Application to black carbon particles. J. Aerosol Sci. 41, 513-521 (2010).

49. Baumgardner, D. et al. Soot reference materials for instrument calibration and intercomparisons: a workshop summary with recommendations. Atmos. Meas. Tech 5, 1869-1887 (2012).

50. Thornberry, T. et al. Persistence of organic carbon in heated aerosol residuals measured during tropical composition cloud and climate coupling (TC4). J. Geophys. Res. 115, D00J02 (2010).

51. Warton, D. I., Wright, I. J., Falster, D. S. \& Westoby, M. Bivariate line-fitting methods for allometry. Biol. Rev. 81, 259-291 (2006).

52. Lack, D. A. \& Cappa, C. D. Impact of brown and clear carbon on light absorption enhancement, single scatter albedo and absorption wavelength dependence of black carbon. Atmos. Chem. Phys. 10, 4207-4220 (2010).

53. Kondo, Y. et al. Consistency and traceability of black carbon measurements made by laser-induced incandescence, thermal-optical transmittance, and filter-based photo-absorption techniques. Aerosol Sci. Technol. 45, 295-312 (2011).

54. Zotter, P. et al. Diurnal cycle of fossil and nonfossil carbon using radiocarbon analyses during CalNex. J. Geophys. Res. 119, 6818-6835 (2014).

55. Crilley, L. R. et al. Sources and contributions of wood smoke during winter in London: assessing local and regional influences. Atmos. Chem. Phys. 15, 3149-3171 (2015).

56. Sandradewi, J. et al. Using aerosol light absorption measurements for the quantitative determination of wood burning and traffic emission contributions to particulate matter. Environ. Sci. Technol. 42, 3316-3323 (2008).

57. Bohren, C. F. \& Huffman, D. R. in Absorption and Scattering of Light by Small Particles 475-497 (Wiley, 1998).

\section{Acknowledgements}

This research was supported by the US Department of Energy Office of Science Atmospheric System Research (ASR) program grant F265 to LANL (PI M.K.D.). A.C.A. acknowledges Director's postdoctoral funding from LANL's LDRD program. C.D.C. was supported by US DOE Award No. DE-SC0008937. The Aerodyne and Georgia Institute of Technology participants were supported by US DOE Award No. DE-SC0006002. The electron microscopy analysis was supported by US DOE grant No. DE-SC0010019. The authors are grateful to the UK Met Office for the use of their NAME dispersion model. We would like to thank David Green of Kings' College London for his assistance in setting up the Detling site. Detling site logistics were supported by the NERC ClearfLo project (Grant ref. NE/H00324X/1)

\section{Author contributions}

The LANL team (S.L., M.K.D., A.C.A, K.G.) led the experimental design, synthesis and analysis of this study. A.C.A., K.G., M.K.D., L.R.W., S.C.H., P.M., E.C.F., P.S.C., W.A.B., J.T.J., L.X. and N.L.N. conducted the measurements. S.L., A.C.A., L.R.W., S.C.H., C.D.C., T.B.O., S.C., N.S., C.M., L.X., N.L.N., S.S. and P.Z. analysed the data and interpreted the results. C.D.C. performed the Mie and RDG modelling. Z.L.F. performed the back trajectory analysis. J.D.A., D.L., A.S.H.P., J.D.L. and D.R.W. contributed to interpretation of the results. S.L., M.K.D., C.D.C. and L.R.W. wrote the manuscript. All authors discussed the results and commented on the paper.

\section{Additional information}

Supplementary Information accompanies this paper at http://www.nature.com/ naturecommunications

Competing financial interests: The authors declare no competing financial interests. 
Reprints and permission information is available online at http://npg.nature.com/ reprintsandpermissions/

How to cite this article: Liu, S. et al. Enhanced light absorption by mixed source black and brown carbon particles in UK winter. Nat. Commun. 6:8435 doi: $10.1038 /$ ncomms9435 (2015). (c) (i) This work is licensed under a Creative Commons Attribution 4.0 International License. The images or other third party material in this article are included in the article's Creative Commons license, unless indicated otherwise in the credit line; if the material is not included under the Creative Commons license, users will need to obtain permission from the license holder to reproduce the material. To view a copy of this license, visit http://creativecommons.org/licenses/by/4.0/ 